\title{
Music festivals as mediators and their influence on consumer awareness
}

\author{
Juan D. Montoro-Pons ${ }^{1}$ and Manuel Cuadrado-García ${ }^{2}$ \\ ${ }^{1}$ Corresponding author: Departamento de Economía Aplicada, \\ Universitat de València, Av. Tarongers sn, 46022 Valencia, Spain. \\ Tel.: +34963828124. Fax: +34963828415. Email: \\ juan.d.montoro@uv.es \\ ${ }^{2}$ Departamento de Comercialización e Investigación de Mercados, \\ Universitat de València, Spain
}

Declaration of interest: none 


\begin{abstract}
Cultural products compete for public awareness in markets with high uncertainty, oversupply and a short product life cycle. Altogether, this means that only a small fraction of all releases generate the necessary consumer awareness to achieve a significant commercial success. This paper aims at identifying the informational function music festivals serve in cultural markets and how it translates into consumer discovery of cultural supply. To do so, we empirically measure informational spillover effects to performers at an established music festival. We hypothesize that this effect stems from the reputation attached to the brand equity of cultural organizations, is asymmetric, as it decreases with the success of the performer such that lesser-known performers profit more than well-known ones. Empirical results are consistent with our hypotheses.
\end{abstract}

Keywords: popular music; creative industries; search costs; consumer discovery; gatekeeping; market creation; reputation; brand equity 


\section{Introduction}

The cultural industries rely on a steady and diversified flow of contents that caters for a heterogeneous and unpredictable demand. This leads to a market with oversupply, a short product life cycle and where only a small fraction of all releases achieve significant commercial success. Altogether, demand is shaped through costly search and discovery due to consumers' uncertainty and lack of knowledge of the choice set they face.

In this setup, attracting consumers' attention is key to understand commercial success and status in cultural markets. Cultural organizations' efforts are oriented towards the attraction of consumers' awareness (Haan and Moraga-González, 2011). On this subject, the literature provides plentiful examples of managerial decisions aimed at increasing the visibility of cultural products both in the film (Einav, 2010; Calantone et al., 2010; Gutierrez-Navratil et al., 2014) and in the music industry (Bourreau et al., 2015; Essling et al., 2017). All these efforts take place within an institutional framework that constrains different agents' strategies and intermediates consumer discovery by economizing on search costs. Put differently, cultural consumption and consumer discovery draw heavily on specific mediators that select, signal and legitimate cultural artifacts and in so doing promote consumer awareness of the cultural supply (Hirsch, 1972).

Cultural mediation is subject to market dynamics and evolution and structural shifts. In recent times, the so-called festivalization of culture has brought about significant changes in the cultural landscape. An interdisciplinary approach underlies the academic research on this process. From a policy perspective, festivalization has been analyzed as a strategy that structures and organizes leisure and cultural activities and that help in the re-shaping of urban spaces for residents and tourists alike (Karpińska-Krakowiak et al., 2009). Besides, Richards (2007) considers the economic impact of festivals and large events in terms of growth and investment. Alternatively, Hitters (2007) identifies festivalization as a trend in cultural policy that uses large cultural events to market cities but that exceeds the framework and objectives of city marketing. This diversity of approaches has led to a diversity of

definitions. Festivalization has been alternatively identified as a process of commodification of cultural manifestations and cultural participation; as the creation of 
spaces of cultural resistance; or as a process through which a cultural event has an impact beyond its temporal and spatial boundaries (Woodward et al., 2014). However, most approaches acknowledge festivalization as the institutionalization of the spatial and temporal concentration of cultural production and consumption, which, in turn, highlights the central position of festivals as agents of primary importance in cultural markets. Notwithstanding, one particular dimension of festivals is their increasing relevance in symbolic value creation, which is at the core of this paper.

In the case of popular music, new consumption ways are changing the outlook of the live industry. Using data for Spain (SGAE, 2018), the audience share of large music festivals has been rising in the past few years, going from $5 \%$ of the total attendance of popular music performances in 2008, to over $21 \%$ in 2017 . Furthermore, large festivals represent in 2017 over $50 \%$ of total income in the sector, up from $20 \%$ in 2008. All in all, new consumption patterns show that festivals emerge as central intermediaries in the popular music market, what strengthens their position in consumer discovery.

This paper analyses the role of music festivals in cultural mediation and consumer discovery vis-à-vis the public awareness that bands attract by being part of the lineup. We posit that, by performing at a reputed festival, bands gain public attention and increase their visibility. This is an information spillover mediated through the affiliation to a high status actor (the festival) and the exposure it attracts both in traditional and new media. In this regard, reputation and its connection to a festival's brand equity are central to understand the magnitude of this spillover effect. The topic is a matter of academic and practical relevance, as it identifies new channels through which gatekeepers spread information and focalize attention on artists, which ultimately facilitates market creation.

To this end, we use a sample of performers in the lineup of three editions of Primavera Sound, a well-known music festival that takes place in Barcelona (Spain). We measure public awareness through the evolution of a web search index to gauge the online behavior of consumers as they become exposed to new information. In other words, changes in the volume of online searches a performer generates are associated to changes in the public attention it creates. As the volume of searches for performers tends to rise simultaneously with specific events (such as the release of albums or videos, going on tour or playing in a reputed festival) we posit it is 
possible to isolate the impact of one of such events. Methodologically, we aim at controlling for changes in the Internet search activity each performer in the sample generates to single out the contribution of participating in a well-known festival.

Two research hypothesis are tested. First, performing at a reputed festival leads to a positive, albeit transient, effect on the volume of web searches performers generate. This increase in Internet search activity is assumed to be an informational spillover effect mediated through the affiliation with reputed actors (Stuart et al., 1999; Rindova et al., 2007; Dubois, 2012). Second, the increase in web searches is expected to be asymmetric: as well-known performers already enjoy a great deal of visibility, the higher the status of the performer, the less the increase in searches. Empirical results support both hypothesis. We find that $77 \%$ of the performers in the sample experience a rise in the volume of searches one week after the festival takes place, and the effect is still significant for $60 \%$ of the performers three weeks after the event. An increase that we show is linked to the informational leverage the festival has. Second, we find robust evidence of the magnitude of this increase being less for better-known artists and superstars.

This work contributes with evidence to the literature of gatekeeping, and the informational role gatekeepers play in cultural markets. Additionally, it provides a new metric, changes in a web search index, to measure the impact of specific events on consumer discovery. Note that, while web search indexes have been already used in the literature mainly for forecasting purposes (Jun et al., 2018), to the best of our knowledge no paper has attempted to analyze the increase in public awareness, measured through search activity, induced by gatekeepers.

The paper is structured as follows. Next the relevant literature is reviewed, including a discussion on gatekeeping, reputation and the role of brand equity. Based on that, the formulation of the two research hypotheses follows. Then a case study dataset is presented and described along with the identification of specific traits of the sample and the performers that form it. The methodology comes next, followed by the testing of the hypotheses and a presentation of the estimation results. The paper closes with a discussion and some concluding remarks. 


\section{Background}

\subsection{The role of cultural mediation}

Cultural consumption is filtered through the discourse of a variety of intermediaries that assess and legitimate the merit of specific manifestations, genres or artists (Shrum, 1991). Terms such as gatekeepers, cultural mediators, intermediaries or brokers have been indistinctly used to refer to the diverse functions that an array of actors serve in cultural markets. From a sociological perspective, symbolic value creation emerges as the central role gatekeepers perform, through selection and classification of cultural production (Hirsch, 1972; DiMaggio, 1987).

Foster et al. (2011), in their analysis of talent selection by live-music programmers, identify the three main functions the literature attributes to cultural organizations that act as gatekeepers. First, gatekeepers not only intermediate in cultural markets but also actively participate in the co-production of cultural contents, which includes successfully managing and bringing to the market cultural projects (Elsbach and Kramer, 2003; Lingo and O'Mahony, 2010). Second, through their tastemaking role, gatekeepers influence the preferences of audiences. This role encompasses the production of tastes through genre classification, criticism and meaning-making of cultural artifacts (DiMaggio, 1987; Shrum, 1991; Allen and Lincoln, 2004). Third, by granting access to cultural markets, they perform a selection (also job-matching or talent allocation) function (Paleo and Wijnberg, 2006).

Janssen and Verboord (2015) expand this range of activities. Besides co-production (which encompasses distributing, co-creating or editing), tastemaking (through marketing and criticism) and selection (through gatekeeping and connecting), the authors include policy oriented functions such as supporting, protecting and censoring. In addition, one could also consider the generation of "buzz" around an artist by mobilising social, cultural and symbolic capital (Scott, 2012). Through this function, in the boundaries of selection and tastemaking, gatekeepers increase the visibility or saliency of specific cultural artifacts. Namely, this implies making the public aware of a specific subset of the cultural supply.

As it is discussed next, the ability of gatekeepers to influence cultural markets through the creation of symbolic value is heavily dependent on its status or reputation as actors in the cultural arena. However reputation is dynamic construct 
that changes with the structural conditions of the mediated markets. In recent times, the generalization of information technologies has challenged the status of mediators (Verboord, 2014; Etter et al., 2019). Online mediation has brought about new actors that are contesting traditional gatekeeping roles, broadening the scope of legitimated discourses that reach the public. This enlargement comes at a cost: as more information becomes available, it is more difficult to separate noise from signal and, in this respect, traditional traditional and new mediators alike need to mobilize resources of all types to to keep their status.

\subsection{Reputation and brand equity}

The influence of intermediaries in cultural markets is asymmetric: not all have an equal sway. The extent to which gatekeepers perform their functions depends on their reputation, that is, their ability to produce beliefs in their judgment (Verboord, 2014). Therefore, symbolic value generation is directly linked to the reputation an actor has, as it signals how efficiently an intermediary generates value in cultural markets and stresses the varying impact different actors have on stakeholder audiences. While most theoretical perspectives tend to agree on the impact reputation has, different approaches underscore differences in its origin (Ravasi et al., 2018). Next we discuss the sociological, the economic-managerial and the institutionalist approaches.

The sociological approach maps actions into collective evaluation, and as such reputation emerges as a social construction (Fine, 2008). From this perspective, reputation reflects the balance of power and/or resources between different players or communities (Lang and Lang, 1988; Bromberg and Fine, 2002). Interestingly, reputation can spill over to associated actors. In this regard, Dubois (2012) undertakes an empirical analysis of the French poetry market and points out selective matching, i.e. being associated with high-status partners, as the most efficient mechanism for building reputation.

Economic and managerial perspectives adopt a signaling approach and draw on asymmetric information (consumers are uncertain about the quality firms supply) to pinpoint reputation as an informational mechanism that reduces uncertainty. It is thus seen as an intangible asset built from within the firm and whose valuation depends on the stakeholders. The managerial literature stresses that brands are 
effective, i.e. credible, signals of unobserved quality and that brand equity stems from the building up of reputation through the allocation of resources (Rao et al., 1999). In other words, brands, as sources of relevant information, convey a value to consumers and brand equity can be defined as the perceived value of the brand signal.

A central question in this setup is how organizations build brand equity. Two mechanisms are identified in the literature. On the one hand, the mobilization of resources to increase an organizations' credibility, which, in turn, reduces consumers' perceived risk and information costs. In this regard, credibility determines the probability of an organization being included in the consideration set of consumers (Erdem and Swait, 1998, 2004). On the other hand, when resources are not available, the affiliation with high-status actors (i.e.brand associations) produces reputational effects spilling over from the brand with a higher equity. Against this background, organizations borrow the reputation of an established brand (Rao et al., 1999) or its efforts. In this sense, Balachander and Ghose (2003) show how marketing strategies permeate to associated brands. Associations create spillover effects to the less familiar brand (Simonin and Ruth, 1998) by filling consumers' informational gaps about quality (Washburn et al., 2000).

A third perspective, the institutionalist approach, stresses the role of institutional intermediaries and the exchanges of information that determine the formation of reputation: the existence of specific market institutions such as contests (Rao, 1994), the undertaking of high levels of value-creating market actions directed to increase a firm's visibility (Rindova et al., 2007), or the association with high reputation actors (Stuart et al., 1999) have been considered within this framework. In a recent empirical application to the arts, Fraiberger et al. (2018) emphasize connections to reputed institutions in the creation of symbolic value. Their research quantifies reputation of artists using the prestige of the museums and galleries where their work has been exhibited. Prestige is measured through the position in a network linking institutions that exhibit same artist(s): centrality in this network is the defining feature of the prestige of an institution. The authors find that artistic reputation emerges through affiliation to specific (i.e. central) museums and galleries. Furthermore, artistic careers exhibit lock-in effects: high-initial reputation artists (those associated at the beginning of their career with the top $20 \%$ institutions) are more 
likely to continue active a decade after their first exhibit than low-initial reputation artists. (those who exhibited at the beginning of their career in the bottom $40 \%$ of the institutions).

Whereas the foregoing approaches differ in the emergence of reputation (from the individual undertaking of an agent through the use of resources of the economic approach to the collective exchanges that take place in the sociological and institutionalist perspective), all three agree on the ability of certain actors, through the affiliation to high status ones, to borrow or capture part of their reputation. Furthermore, by focusing on different sources of reputation, the different approaches provide a complementary view of the process of its accumulation. In this regard, Rindova et al. (2005) integrate both the economic and institutional approaches and define a multidimensional measure of reputation. In their empirical model firms use resources to signal quality while institutional intermediaries and high-status actors, by creating disparities in information, have a strong influence on a firm's prominence.

\section{Music festivals as mediators}

Against this background, we analyze the role of music festivals as cultural mediators that create symbolic value that benefits audiences inasmuch as they spread information and, by and large, reduce the uncertainty related to cultural consumption. In this gatekeeping role, we identify three basic functions music festivals perform.

Firstly, music festivals coproduce cultural products by combining the output from different creators into a lineup, which generally exhibits a hierarchical structure by pooling more successful (therefore less risky for consumers) performers along with lesser-known (and more unpredictable) ones. Secondly, music festivals act as selectors by performing a search and selection of talent task. In so doing, they choose which cultural products are offered acting as signaling devices that reduce consumers' search costs and trigger consumer discovery. Thirdly, festivals prescribe and shape the taste of audiences. They do so through the design and structure of the lineup, by including specific performers, but also at a higher level through the legitimization of and support to specific genres.

These three aspects can be identified in the economics and management literature. Within this context, festivals are portrayed as supply-side institutional 
arrangements whose flexibility fosters a more innovative and less constrained programming, which, on the other hand, is expected to have an impact on cultural demand (see Frey, 1994, for a discussion on the incentives consumers and organizations face in the market of festivals).

Besides, festivals as reputable actors generate information spillovers that signal, certificate and classify cultural supply (Paleo and Wijnberg, 2006). In so doing, consumers' uncertainty and search costs are significantly reduced, which influences the commercial performance of artists. Moreover, the efficiency of this signaling role is directly related to the reputation a festival holds. In this respect, evidence suggests that attendance at music festivals is mainly driven by the reputation (attached to the brand equity) of the festival and not the program itself (Leenders, 2010). Attendees shift their focus from the specific cultural content (lineup of performers, artists or bands) to the gatekeeper, as it signals the expected quality of the experience.

The coproduction function of music festivals has been analyzed by Hiller (2016), who identifies which factors affect the programming decisions, that is, who performs and what is the hierarchy of bands in the festival. The basic problem of cultural markets, i.e. the asymmetry of information and costly consumer search, gives festivals an informational leverage they can exploit by arranging and marketing a lineup that combines well-known successful bands with lesser-known ones. To the extent that bundling allows certain markets to exist (the so called market creation effect), it is unambiguously beneficial, as performers unknown to the large public borrow the credibility of better-known ones. From this perspective, bundling signals quality and helps consumers to reduce uncertainty and economize in search costs. On the other hand, given the repeated nature of the interaction with consumers, festivals have incentives to maintain the quality of their proposal, i.e. their reputation, even though it would be hard for consumers to ascertain it ex-ante.

Can the influence of festivals in cultural markets be exclusively related to bundling? Note that, if this were the case, there could be no informational leverage without a lineup. But reality tells us otherwise, an example being well-established festivals that start selling tickets even before the lineup is known. In this respect, bundling alone, which is based on physically tying diverse products such that one (unknown to the public) borrows the reputation from the other (whose quality consumers can assess), cannot fully explain this informational role of festivals. As Choi (2003) 
points out, bundling is just one of the many alternatives organizations use to exploit their informational leverage. Interestingly, Hiller (2016) explicitly bases the expected quality of the unknown performer in the lineup on the reputation of the festival itself, shifting the focus from the quality of the bands in the lineup to the brand equity of the festival.

This research draws on the reputation of a festival (embedded in its brand equity) to signal the quality of the lineup. By performing this function, festivals generate informational spillover effects that raise the public awareness of performers and, therefore, enlarge their potential market.

\section{Research hypotheses}

We test the role of music festivals in the process through which consumers filter and incorporate new information. To do so, we consider festivals as an association between a high status actor and specific performers. Next, we measure how this association affects the prominence or public awareness of artists.

In order to make the concept of awareness operational, we use the evolution of a web search index. We posit that performers' increase in public awareness is reflected on an increase in the volume of Internet queries they attract. The aim is to identify the amount of the change in the volume of searches that can be attributed to the association with the festival. In other words, we are interested in knowing if playing at a festival enhances the visibility of performers through the increase in web searches they generate.

Our primary research hypothesis, on the increase on performer's public awareness, reads as follows:

H1 Being in the lineup of a music festival increases performers' public awareness.

Hypothesis $\mathbf{H 1}$ formulates the existence of an informational spillover from the reputation of the festival to individual performers. However, and given the temporal nature of the association with the music festival and the continuous flow of new cultural content in the market, consumers' attention will be constantly changing. This makes the proposed effect to be temporary.

H1b The increase in performers' public awareness is limited in time. 
Secondly, we hypothesize the expected increase in awareness to be asymmetric. The rationale beyond this asymmetry is as follows: more successful acts (one may think of superstars) already command the attention of the public in that audiences are already aware of their music. In this case, being associated with a festival and its lineup may be of limited value. On the other hand lesser-known performers may benefit most from the affiliation with a high status actor, its brand and its varied lineup, which includes more successful acts. That is to say, spillover effects in the case of lesser-known acts may be significantly greater, as these materialize from the increase in their visibility to wider audiences channeled through the festival. Therefore, we formulate the following hypothesis:

H2 The increase in the web search activity decreases with a performer's success.

Note that testing hypothesis $\mathbf{H} \mathbf{2}$ calls for a classification of performers. To this end a measure of relative awareness is proposed: the volume of Internet searches a performer generates as compared with the volume of searches the festival generates provides us with a contextual ranking of performers against which to test the expected asymmetry.

\section{Data and methods}

\subsection{The dataset}

We collected data of performers in the Primavera Sound, a well-established music festival that takes place annually in Barcelona (Spain) since 2001. In its 2018 edition it attracted an audience of over 208,000 attenders to 242 performances spread over four days, from May 30th to June 2nd. The sample includes 73 headliners that performed at the 2016, 2017 and 2018 editions.

The metric used to measure a performer's public awareness is the Google Trends search index. It is an unbiased sample of search data over a period of time (in our case, on a weekly basis) translated into a normalized 0-100 index, such that the week with the maximum volume of queries is set as 100 and all other weeks are given relative weights. Some key features of the data collection:

1. Google Trends allows to control the geography generating the queries: in our case the goal was to measure the increase in searches generated in Spain. 
Nevertheless, and for predictive purposes, web searches in a control geography (Australia) were also collected. We discuss this later.

2. Data gathering was automated through the use of an application programming interface (API) for Google Trends ${ }^{1}$.

3. To disambiguate the search terms, we use the suggestions functionality of Google Trends, which allows us to unambiguously select only the queries that refer to a performer's name. ${ }^{2}$

4. In order to test $\mathbf{H 2}$, performers are to be classified or ranked, hence a relative measure of awareness is needed. To do this, the Google Trends weekly search index for the festival was also employed. Therefore, the volume of web searches for each performer in Spain was retrieved twice: as a single query; and together with the search term "Primavera Sound".

Two comments apply. First, the choice of performers, i.e. headliners, is based on their prominent position in the festival's lineup poster. Note that this does not imply a homogeneity of superstar acts and indeed the variability in the popularity of the sample units is large, as it is next described. However, this allows us to avoid problems related to the process through which the index is constructed, as search terms that do not generate enough queries are automatically assigned an index value of zero, creating a downward-bias problem. Namely, we need each search term to produce enough queries, something that is not guaranteed for all performers at the festival. Second, when comparing two search terms (performer and festival) 100 is set for the value of the term that attains the largest volume of queries; all other search values are rescaled accordingly.

The dataset includes, when available, roughly five years worth of search data for each performer: each time series spans a period that starts 253 weeks before the

\footnotetext{
${ }^{1}$ https://github.com/GeneralMills/pytrends. Alternatively, there is a R package, gTrendsR that offers the same functionality.

${ }^{2}$ When a query is run for a search term like "Suede" (a band performing in the 2016 edition of the festival), several results are returned. Among them "Suede: Topic", "Suede: Shoe store in Rome, Italy" and "Suede: Band". Each of the outcomes comes with a unique code identifying each query term. We performed this procedure on all the performer's names in the sample selecting only the codes that identified the performers.
} 
festival takes place and ends 6 weeks after it. Figure 1 illustrates the pattern in the evolution of searches over time for two performers in the sample: PJ Harvey (top) and Jane Birkin (bottom). It includes a reference line at the week the festival takes place. Note that the observed effect, while visible in both, is stronger in the top plot. Altogether it suggests performer-dependent shifts in the search activity that could be explained by the association with the festival.

In addition, after jointly retrieving the volume of searches for each performer and the festival, a relative measure of the searches each performer $i$ generates (ratio of awareness) is calculated:

$$
\text { ratio }_{\text {it }}=\frac{\text { search volume performer } i \text { in week } t}{\text { search volume festival in week } t}
$$

Note it is positive without an upper bound, such that at any point it will be over 1 if the performer generates more searches than the festival does, and below 1 otherwise. The awareness of an act vis-à-vis the festival provides a relative measure of the brand equity of the latter: the smaller the ratio the stronger the informational role of the festival. This, in turn, allows us to classify performers in terms of their relative saliency in the music market.

A detailed summary of the dataset, listing all performers, is available in the appendix (table 4). For each performer in the sample it includes: year of the first release (spanning from 1977 to 2015, which shows a mix of established and newer acts); genre of the performer (as classified by Pitchfork.com); sample mean index of web searches (Web); sample mean value of the ratio of awareness (Ratio); and edition (Year) of the festival.

\subsubsection{The status of performers}

Once the ratio of awareness is computed, we proceed to rank and classify performers in the sample. To do so, we turn to figure 2, which plots the distribution of the ratio for each performer. A reference line at one is included: values of the ratio above it identify points at which performers generate more searches than the festival; on the contrary, values below the reference line indicate the volume of searches for the festival is greater. Most measurements are less than one, which implies that, in most cases, the festival generates more searches than individual performers. This, 
in turn, provides descriptive evidence on a festival's informational leverage and its potential to create spillover effects.

Using the distribution of the ratio, performers can be classified into four groups. Each one is segmented in figure 2 using a dashed vertical line. Firstly, there are some performers (35\% of the sample) whose ratio is always zero, meaning that the amount of searches they generate is negligible compared to that of the festival. Note that zero does not imply no searches, but that they are relatively small when compared to those generated by the festival. These are what we label as lesser-known performers. Secondly, performers whose ratio is greater than zero but less than one are classified as middle class. These form the largest group in the sample (37\%). Thirdly, instances in which the distribution of the ratio includes one are labeled as upper middle class. Finally, in very specific cases (three overall) performers generate more searches, on the median, than the festival itself: these are labeled as superstars. Note that on practical grounds we group upper middle class and superstars: both groups make $28 \%$ of the performers in the sample.

\subsubsection{The descriptive evidence}

Figure 3 plots, for each performer, the average search index after the festival takes place (vertical axis) against the search index of the whole sample (horizontal axis). It also includes a 45 degree line, which depicts the points where the average index after the festival is equal to the average index for the whole sample. Points above the line indicate that a performer experiences a surge in searches after the festival takes place, while points below it indicate a performer undergoes a dip in searches. In addition, the size of each data point is proportional to the ratio of awareness of each performer.

Two features emerge from a descriptive analysis of the sample. First, for most performers the average search index after the festival takes place is greater than that of the whole sample. As most points lie above the 45 degree line, the descriptive evidence suggests that most performers in the sample attract (on average) a greater volume of searches after the festival takes place. This finding is consistent with the hypothesis that being associated with the festival generates an informational spillover effect.

Second, those who experience a greater increase in the volume of searches are 
not the most successful acts. Bigger dots are mostly around the 45 degree line. In comparison, those further above the line (performers that experience the largest boost in searches) are smaller in size (i.e. lesser-known and middle-class performers). Specifically, performers that experience the largest increase in absolute searches are also those with medium to low relative awareness.

Therefore, the descriptive evidence is suggestive of the research hypotheses $\mathbf{H 1}$ and $\mathbf{H} 2$.

\subsection{Measuring informational spillovers}

To test the contribution of the festival to the observed discrete jump in web searches, the empirical framework borrows from the literature on event studies (MacKinlay, 1997; Sorescu et al., 2017) in that it forecasts a counterfactual of web searches had the festival not taken place and from difference-in-differences methods where a control market is used.

The method proceeds stepwise. For each performer in the sample, we take the time series of the Google Trends index and (i) split it into two sets (pre-treatment and post-treatment period); the cutoff point is given by the week the festival takes place. (ii) The pre-treatment period is used to estimate a structural time series model of the volume of searches. (iii) This model is employed to predict searches in the post-treatment period. We do that for different time horizons: one and three weeks after the festival takes place. These predictions are considered as a counterfactual, i.e. the volume of searches had the festival not taken place. (iv) A comparison of the actual volume of searches against predicted (or counterfactual) provides an estimate of the increase in web searches that can be attributed to the association with the festival. In this way, we estimate the distribution of the impact across performers and not just the mean impact for the sample. ${ }^{3}$

However, and contrary to event studies where a linear model is the most frequent specification, we use a flexible approach that incorporates unobserved time series

\footnotetext{
${ }^{3}$ We should note that a reviewer suggested a regression discontinuity approach using time as assignment variable. Besides specific methodological problems, such as the non-randomized nature of the assignment variable and the specification of the time series model (Lee and Lemieux, 2010; Hausman and Rapson, 2018), this approach would produce an estimate of the average effect preventing any inference on the distribution of the impact.
} 
components and control variables. In this regard, we follow Brodersen et al. (2015) to produce a counterfactual using a structural time series (STS) model with contemporaneous covariates (see also Varian, 2014). STS models capture latent traits in the evolution of the time series that cannot be explained by observed trends or covariates. Nevertheless, they are flexible enough as they accommodate control variables to account for specific changes in the search index due to observed events. Thus, STS models produce a forecast by combining the underlying dynamics of the time series plus information about market innovations that, being global in nature, attract the interest of Internet users. Examples of these events are the release of new music, a new album or video. Namely, STS models provide a bridge between regression and time series models (Harvey, 2006).

The specification of the model is as follows. The index of web searches of performer $i$ at week $t$ is denoted by $y_{i t}$. It is assumed $y$ depends on a set of observed covariates $x_{i t}$ and latent state variable(s) $z_{i t}$. Then:

$$
\begin{aligned}
y_{i t} & =\beta x_{i, t}+H z_{i, t}+\epsilon_{t} \\
z_{t+1} & =B z_{t}+\eta_{t}
\end{aligned}
$$

with $\epsilon \sim N\left(0, \sigma^{2}\right)$ and $\eta_{t} \sim N\left(0, \tau^{2}\right)$. Equation (1) regresses $y$ on observed $x$ and unobserved $z$ variables; equation (2) defines the dynamics (change over time) of the unobserved part of the model. Two decisions are to be made: first, what observed variables $x$ to include; second, what latent (or structural) components $z$ to choose.

As for the former, ideally, we expect $x_{i t}$ to capture all events that affect web searches a performer generates other than the festival. To this end, we exploit geographical and scope information on Google Trends: we select the search index in a control geography that, it is assumed, incorporates all the relevant information about the performer while remaining unaffected by the music festival taking place. Australia is chosen, as there are logistics reasons (cost barriers) that prevent performers touring in Europe to perform there during the forecasting period. Moreover a moderate to large correlation between searches in Spain and Australia is found for performers in the sample. Additionally, as one should expect, the index of searches for the music festival in Australia was irrelevant when compared to the searches that most of the performers commanded there in the period studied. Hence expression (1) includes web $\left(x_{1, i t}\right)$ and YouTube $\left(x_{2 i, t}\right)$ search indexes for performers in 
Australia.

As for the unobserved component, $z_{i t}$, different specifications were formulated and a local level $\mu_{i t}$ was chosen based on the predictive power against a random walk with a drift. ${ }^{4}$ The model specification is then:

$$
\begin{aligned}
y_{i t} & =\mu_{i t}+\beta_{1} x_{1, i t}+\beta_{2} x_{2, i t}+\epsilon \\
\mu_{t} & =\mu_{i t-1}+\eta_{t}
\end{aligned}
$$

Model estimation is carried out using 10,000 Markov chain Monte Carlo samples.

\section{$6 \quad$ Results}

\subsection{Evidence on the surge of web searches}

Once model (1)-(2) is estimated for each performer, the increase in the volume of searches (difference between actual and predicted search indices) and its standard error are calculated and the corresponding p-value is obtained. Table 1 summarizes the main results, while detailed results for all performers are displayed in the appendix (table 5). Additionally, figure 4 shows individual significant $(\mathrm{p}$-value $<0.1)$ results: performers are sorted according to the magnitude of the increase in the search index, and point estimates, as well as 95\% confidence levels, are displayed.

It is noteworthy that $77 \%$ of the estimate effects are significant one week after the festival has taken place. Performers experienced a rise in the index of web searches that on average was equal to 31.5 points (note the index ranges from 0 to 100), implying a $245 \%$ average relative increase in the search volume. Overall, we find these results to be consistent with hypothesis H1. Furthermore, after increasing the prediction window from one to three weeks still $60 \%$ of performers benefit from being associated with the festival. The average performer undergoes an increase in searches of 19 points (a 195\% increase).

However, as expected, the magnitude and number of performers whose searches experience a significant rise declines over time as the effect fades and/or the standard error of the estimate increases. This transitory effect (consistent with $\mathbf{H 1 b}$ ) could be

\footnotetext{
${ }^{4}$ Other combinations of components that were tested: local linear trend and generalized trend models with or without seasonal components. None was favored by the data.
} 
explained due to the short life cycle in the music market with consumers constantly becoming exposed to new information.

Note that a zero or, for that matter, a non-significant spillover effect implies the festival does not generate a surge in awareness. Given the theoretical framework put forward, two, non-competing, cases are consistent with it: (1) well-known performers (i.e., upper middle class or superstars) whose awareness is largely unaffected by the festival and only achieve a marginal surge in searches; (2) estimates whose precision is severely affected by large standard errors.

Figure 5 plots the distribution of the increase of the volume of searches group by genre of the performer. Taking into account the median of the increase, and disregarding underrepresented genres, rap performers stand out, followed by rock acts (a genre in which outliers pull up the average increase). On the opposite end of the spectrum stands pop music, which also shows the greatest spread: this could be related to the potential ambiguity of the genre that, in turn, includes the least homogeneous group of performers in the sample.

\subsection{Spillover effect asymmetries}

The awareness-enhancing effect of being associated with a highly reputed actor is hypothesized to be unevenly distributed, as better-known performers and superstars already attract the attention of the public. Namely, the increase in the volume of searches is expected to be greater for lesser-known performers.

To test it, we draw on the classification of performers by their relative success using the ratio of awareness (see figure 2), that clusters performers into three categories: lesser-known (L), middle-class (M) and upper middle class and superstars (U). Table 2 shows the average absolute and relative increase in the volume of searches by performer type. It shows that both the average $\mathrm{L}$ and $\mathrm{M}$ performer experience a greater absolute increase (34-36 points) than the average U performer (roughly 23 points). In relative terms, web search increase by performer type is on average equal to $330 \%$ (L), 225\% (M) and 179\% (U). Overall, both provides descriptive evidence of the asymmetric impact of being associated with the festival.

Additionally, the distribution of absolute increase in web searches grouped by performer type (figure 6) shows a declining average effect as the relative awareness of the performer increases, while the median increase in the volume of searches has 
an inverted U-shape: greater for $\mathrm{M}$ than for $\mathrm{L}$ and $\mathrm{U}$ bands. Nevertheless, the existence of extreme values on the upper tail of the distribution for the lesser-known performers implies an average effect remarkably larger for this group of performers.

Next, we pool all the data on individual searches to build a panel dataset and estimate a fixed effects model with autoregressive disturbances. The use of a regression model approach is adequate for two reasons. On the one hand, we are interested in finding average effect on groups (L, M and U) of performers, something that can only be achieved by combining (pooling) the dataset of performers. On the other hand, this can be seen as a robustness exercise of the estimates provided in the previous section.

The dependent variable is the index of web searches in Spain and the key independent variable is the association with the festival, which we assume is a discrete jump in the index that lasts $t$ weeks after the festival. It enters the model as three intervention effects, one for each band type: Band L, Band $M$ and Band $U$. Note that, in contrast to the analysis in the preceding section where an effect for each performer is estimated, now we estimate the average impact for each performer group.

The use of a fixed effects model allows us to incorporate time-invariant unobserved heterogeneity at the performer level. Moreover, we include additional control variables: (i) the index of web searches in Australia; (ii) a dummy variable to control for a discontinuous jump in searches the week when the lineup is announced; (iii) the time (in years) since a band released its first album and its square. Table 3 shows the estimation results, considering the intervention effect lasts $t$ weeks, with $t$ being equal to one, two, four and six weeks. Based on the information criteria (AIC and BIC), the preferred model is $t=2$, meaning that the effect of participating at the festival on web search activity lasts two weeks after the festival ends. Moreover, tests on the coefficients support the quantitative effect to be equal for L and M performers, which, in turn, are greater than the effect for U performers. The Internet volume of searches of the average L/M band increased by roughly 28 points, while that for the average $\mathrm{U}$ band was roughly 22 points. Finally, a likelihood ratio test favors the proposed model against one with a homogeneous increase in web searches across all band types.

One comment is in order. Note that this setup tests the magnitude of the absolute 
effect, that is, the average point increase in the value of the web search index (equal for $\mathrm{M}$ and $\mathrm{L}$ performers). This tells nothing about the relative effect unless we know (or have an estimate of) the level of the index without the intervention, which under the STS specification was computed as a counterfactual. As an exercise, we can use the sample mean web index as a naive estimate, which is equal to 13.3 for L-bands and 17.2 for M-bands. A back-of-the-envelope calculation yields a 209\% relative increase for the average $\mathrm{L}$ band and a $166 \%$ increase in the average $\mathrm{M}$ band. In short, the same absolute effect leads to different relative effects (larger for L performers). Nevertheless this should be taken as a rough approximation for illustration purposes.

Overall, these results support $\mathbf{H} \mathbf{2}$ and provide a robustness check for $\mathbf{H 1}$. Additional checks were performed, namely dropping web searches in Australia and estimating alternative random effects and fixed effects methods, without the foregoing conclusions being altered. ${ }^{5}$

\section{Discussion}

The sheer amount of supply in the creative industries and the uncertainty regarding its quality creates an informational shortage that consumers address by relying in specific market institutions. The media (both traditional and digital), criticism, contests and prizes, stardom, or organizations that connect content creators and consumers, are examples of the variety and complexity of the institutional arrangements that emerge in cultural markets to solve this informational asymmetry, reduce uncertainty and enlarge the market. This paper has analyzed the purpose music festivals serve, acting as gatekeepers, in popular music, and how these contribute to the creation of cultural markets by spreading knowledge among consumers and raising the awareness on the available cultural supply.

It has been argued how festivals co-produce (along with content creators) a cultural output and serve a signaling function in the market that, by raising awareness on artists, helps consumers identify the choice set they face and, ultimately, shapes their tastes. The product of music festivals, the lineup, bundles a hierarchy of acts whose prominence among consumers is skewed. This diversity of performers implies

\footnotetext{
${ }^{5}$ For clarity sake we exclude them from the paper, although can be provided on request.
} 
the uncertainty surrounding quality is asymmetric, with lesser-known performers carrying greater uncertainty or risk from the consumer perspective. It is through their association with a high status actor that uncertainty is reduced and informational gaps are filled. The informational leverage of festivals, reflected in its brand equity, allows performers to borrow their reputation and gain public awareness and credibility.

From this perspective, by granting access to markets and fostering consumer discovery, festivals have a direct market creation effect, which, ultimately, facilitates innovation in popular music. In this regard, two comments are in order. First, the relevance of festivals in their gatekeeping functions is expected to increases with the growing tendency towards the festivalization of the live music industry. Second, the quality signaling role of festivals is not restricted to influence attendees but the public in general through the impact these events have on the traditional and digital media. In short, the informational role described is expected to extend beyond actual audiences.

Using an empirical approach, the research presented has analyzed and statistically tested informational spillover effects on acts participating in a reputed music festival. More specifically, a case study on performers participating in three editions of the Primavera Sound has been carried out, where data on Internet searches have been analyzed through a combined structural time series and panel data framework, seeking for evidence on the magnitude and asymmetry of spillover effects as measured through increased Internet searches. Empirical findings support the hypotheses put forward.

In this regard, it is found that $77 \%$ of the performers experience a (statistically significant) discrete jump in public awareness, as measured by the volume of Internet searches in the geography where the festival takes place. However, this initial impact fades as one moves ahead from the intervention point. Results were robust when the empirical procedure was inverted to infer the impact of a non-existent market intervention in the control geography: these turned out to be non-significant.

On the other hand, results are also consistent with the nonlinearity of this spillover effect. The impact of playing at the festival was significantly greater for lesser-known and middle-class performers, implying that the more successful the band, the less the increase in awareness. In this case, the evidence is consistent with 
the time-span of the average informational spillover being short-lived (two weeks) after the festival.

Taking both results into account, the applied implications in terms of how innovations and the development of artistic careers are managed in the festivalized music industry are two-sided. On the one hand, participating in festivals with large brand equity can be a springboard for lesser-known performers, who, by leveraging on the brand value of the event, can spread awareness and increase consumers' attention and, maybe, the fan base, hence raising the prospects of future success. On the other hand, the evidence of these spillover effects gives established festivals, which command a reputation on audiences, an additional bargaining power to negotiate contracts with lower monetary compensation in exchange for these indirect returns through enhanced awareness.

From an empirical research standpoint, this paper provides a framework to measure the value of specific organizations to artists in cultural markets based on the informational content they provide to consumers. In this respect, changes in online web searches after an event provide interesting insights on what attracts consumers' interest and its correlates. Besides, the ratio of searches (performer to organization) allows to identify the relative brand value of performers and to rank them accordingly. Furthermore, it contributes to the literature in two additional ways. First, it offers an empirical approach to identify the impact of specific events on the changes in awareness or visibility of an actor; this can be crucial when actors compete for consumer's attention. Second, it provides a metric, based on relative public awareness, to classify and rank content providers in cultural markets when no clear-cut measure exists to that end.

Theoretically, one might consider that spillover effects are generated at the performers level, with superstar bands lending credibility to lesser-known ones. This implies that bundling and not the brand equity of the festival explains the observed evolution of searches. Even if this were the case, one could argue that this effect is mediated through the festival, which, to some extent, acts a bilateral platform connecting performers and audiences. In this role, the festival creates value by putting together a lineup that adds credibility to (most) performers through the associations it fosters. Therefore the central part such events play in channeling and spreading information in the market. On the other hand, and from an empirical standpoint, 
the attention raised by the festival analyzed in this paper is in most cases greater than that by individual performers as figure 2 illustrates. This, we believe, justifies the approach undertaken.

To conclude, the empirical evidence provided in this paper stresses the relevance of the informational role of cultural organizations and how it translates into discovery and market creation. Certainly, results are dependent on the reputation (reflected on the brand equity) of the specific organization considered, as it determines the value consumers attach to its signaling role. However, our findings illustrate the stylized facts under consideration: music festivals spread information and in so doing reduce uncertainty in consumption and raise the awareness of specific performers. Furthermore, and with regard to the potential of the strategy developed, it should be noted that the proposed empirical analysis provides both a framework and a metric for analyzing central issues in cultural supply and consumption, such as the role of specific institutions in creating and innovating in cultural markets.

\section{References}

Allen, M. P. and A. E. Lincoln (2004). Critical discourse and the cultural consecration of American films. Social Forces 82(3), 871-894.

Balachander, S. and S. Ghose (2003). Reciprocal spillover effects: A strategic benefit of brand extensions. Journal of Marketing 67(1), 4-13.

Bourreau, M., P. Doğan, and S. Hong (2015). Making money by giving it for free: Radiohead's pre-release strategy for in rainbows. Information Economics and Policy 32, 77-93.

Brodersen, K. H., F. Gallusser, J. Koehler, N. Remy, S. L. Scott, et al. (2015). Inferring causal impact using Bayesian structural time-series models. The Annals of Applied Statistics 9(1), 247-274.

Bromberg, M. and G. A. Fine (2002). Resurrecting the red: Pete Seeger and the purification of difficult reputations. Social Forces 80(4), 1135-1155.

Calantone, R. J., S. Yeniyurt, J. D. Townsend, and J. B. Schmidt (2010). The effects 
of competition in short product life-cycle markets: The case of motion pictures. Journal of Product Innovation Management 27(3), 349-361.

Choi, J. P. (2003). Bundling new products with old to signal quality, with application to the sequencing of new products. International Journal of Industrial Organization 21(8), 1179-1200.

DiMaggio, P. (1987). Classification in art. American Sociological Review, 440-455.

Dubois, S. (2012). Recognition and renown, the structure of cultural markets: evidence from French poetry. Journal of Cultural Economics 36(1), 27-48.

Einav, L. (2010). Not all rivals look alike: Estimating an equilibrium model of the release date timing game. Economic Inquiry 48(2), 369-390.

Elsbach, K. D. and R. M. Kramer (2003). Assessing creativity in Hollywood pitch meetings: Evidence for a dual-process model of creativity judgments. Academy of Management journal 46(3), 283-301.

Erdem, T. and J. Swait (1998). Brand equity as a signaling phenomenon. Journal of Consumer Psychology 7(2), 131-157.

Erdem, T. and J. Swait (2004). Brand credibility, brand consideration, and choice. Journal of Consumer Research 31(1), 191-198.

Essling, C., J. Koenen, and C. Peukert (2017). Competition for attention in the digital age: The case of single releases in the recorded music industry. Information Economics and Policy 40, 26-40.

Etter, M., D. Ravasi, and E. Colleoni (2019). Social media and the formation of organizational reputation. Academy of Management Review 44(1), 28-52.

Fine, G. A. (2008). Reputation. Contexts 7(3), 78-79.

Foster, P., S. P. Borgatti, and C. Jones (2011). Gatekeeper search and selection strategies: Relational and network governance in a cultural market. Poetics 39(4), $247-265$. 
Fraiberger, S. P., R. Sinatra, M. Resch, C. Riedl, and A.-L. Barabási (2018). Quantifying reputation and success in art. Science 362(6416), 825-829.

Frey, B. S. (1994). The economics of music festivals. Journal of Cultural Economics 18(1), 29-39.

Gutierrez-Navratil, F., V. Fernandez-Blanco, L. Orea, and J. Prieto-Rodriguez (2014). How do your rivals' releasing dates affect your box office? Journal of Cultural Economics 38(1), 71-84.

Haan, M. A. and J. L. Moraga-González (2011). Advertising for attention in a consumer search model. The Economic Journal 121(552), 552-579.

Harvey, A. (2006). Forecasting with unobserved components time series models. Handbook of economic forecasting 1, 327-412.

Hausman, C. and D. S. Rapson (2018). Regression discontinuity in time: Considerations for empirical applications. Annual Review of Resource Economics 10, $533-552$.

Hiller, R. S. (2016). The importance of quality: How music festivals achieved commercial success. Journal of Cultural Economics 40(3), 309-334.

Hirsch, P. M. (1972). Processing fads and fashions: An organization-set analysis of cultural industry systems. American Journal of Sociology 7r(4), 639-659.

Hitters, E. (2007). Porto and Rotterdam as European capitals of culture: Toward the festivalization of urban cultural policy. Cultural tourism: Global and local perspectives, 281-301.

Janssen, S. and M. Verboord (2015). Cultural Mediators and Gatekeepers, pp. 440446.

Jun, S.-P., H. S. Yoo, and S. Choi (2018). Ten years of research change using Google Trends: From the perspective of big data utilizations and applications. Technological Forecasting and Social Change 130, 69-87.

Karpińska-Krakowiak, M. et al. (2009). Festivalization of the city. contemporary examples. Lidé města (Urban People) 11(2), 338-350. 
Lang, G. E. and K. Lang (1988). Recognition and renown: The survival of artistic reputation. American Journal of Sociology 94(1), 79-109.

Lee, D. S. and T. Lemieux (2010). Regression discontinuity designs in economics. Journal of economic literature 48(2), 281-355.

Leenders, M. A. (2010). The relative importance of the brand of music festivals: a customer equity perspective. Journal of Strategic Marketing 18(4), 291-301.

Lingo, E. L. and S. O’Mahony (2010). Nexus work: Brokerage on creative projects. Administrative Science Quarterly 55(1), 47-81.

MacKinlay, A. C. (1997). Event studies in economics and finance. Journal of economic literature 35(1), 13-39.

Paleo, I. O. and N. M. Wijnberg (2006). Classification of popular music festivals: A typology of festivals and an inquiry into their role in the construction of music genres. International Journal of Arts Management, 50-61.

Rao, A. R., L. Qu, and R. W. Ruekert (1999). Signaling unobservable product quality through a brand ally. Journal of Marketing Research, 258-268.

Rao, H. (1994). The social construction of reputation: Certification contests, legitimation, and the survival of organizations in the American automobile industry: 1895-1912. Strategic Management Journal 15(S1), 29-44.

Ravasi, D., V. Rindova, M. Etter, and J. Cornelissen (2018). The formation of organizational reputation. Academy of Management Annals 12(2), 574-599.

Richards, G. (2007). The festivalization of society or the socialization of festivals? the case of catalunya. Cultural tourism: Global and local perspectives, 257-280.

Rindova, V. P., A. P. Petkova, and S. Kotha (2007). Standing out: How new firms in emerging markets build reputation. Strategic Organization 5(1), 31-70.

Rindova, V. P., I. O. Williamson, A. P. Petkova, and J. M. Sever (2005). Being good or being known: An empirical examination of the dimensions, antecedents, and consequences of organizational reputation. Academy of Management Journal 48(6), 1033-1049. 
Scott, M. (2012). Cultural entrepreneurs, cultural entrepreneurship: Music producers mobilising and converting bourdieu's alternative capitals. Poetics 40(3), $237-255$.

SGAE (2018). Anuario SGAE de las artes escénicas, musicales y audiovisuales (http://www.anuariossgae.com/home.html).

Shrum, W. (1991). Critics and publics: Cultural mediation in highbrow and popular performing arts. American Journal of Sociology 97(2), 347-375.

Simonin, B. L. and J. A. Ruth (1998). Is a company known by the company it keeps? assessing the spillover effects of brand alliances on consumer brand attitudes. Journal of marketing research, 30-42.

Sorescu, A., N. L. Warren, and L. Ertekin (2017, Mar). Event study methodology in the marketing literature: an overview. Journal of the Academy of Marketing Science 45(2), 186-207.

Stuart, T. E., H. Hoang, and R. C. Hybels (1999). Interorganizational endorsements and the performance of entrepreneurial ventures. Administrative Science Quarterly 44(2), 315-349.

Varian, H. R. (2014). Big data: New tricks for econometrics. Journal of Economic Perspectives 28(2), 3-28.

Verboord, M. (2014). The impact of peer-produced criticism on cultural evaluation: A multilevel analysis of discourse employment in online and offline film reviews. New Media \& Society 16(6), 921-940.

Washburn, J. H., B. D. Till, and R. Priluck (2000). Co-branding: brand equity and trial effects. Journal of Consumer Marketing 17(7), 591-604.

Woodward, I., J. Taylor, and A. Bennett (2014). The Festivalization of Culture. Ashgate Publishing, Ltd. 


\begin{tabular}{lrr}
\hline & Absolute effect & Relative effect \\
\hline One week & 31.5 & 2.45 \\
Three weeks & 19.0 & 1.45 \\
\hline
\end{tabular}

Table 1: Summary of results: average absolute increase in search index, average relative increase in search index

\begin{tabular}{lrr}
\hline Performer type & Absolute effect & Relative effect \\
\hline $\mathrm{L}$ & 36.01 & 3.30 \\
$\mathrm{M}$ & 34.63 & 2.25 \\
$\mathrm{U}$ & 22.86 & 1.79 \\
\hline
\end{tabular}

Table 2: Summary of results grouped by performer type. 


\begin{tabular}{|c|c|c|c|c|}
\hline & \multicolumn{4}{|c|}{ Length of effect $t$ (in weeks) } \\
\hline & $t=1$ & $t=2$ & $t=4$ & $t=6$ \\
\hline \multirow[t]{2}{*}{ Web AUS } & $0.2651^{*}$ & $0.2645^{*}$ & $0.2643^{*}$ & $0.2634^{*}$ \\
\hline & $(0.0083)$ & $(0.0083)$ & $(0.0083)$ & $(0.0083)$ \\
\hline \multirow[t]{2}{*}{ Years } & -0.1924 & $-0.2911^{*}$ & $-0.3404^{*}$ & $-0.3529 *$ \\
\hline & $(0.1461)$ & $(0.1453)$ & $(0.1472)$ & $(0.1488)$ \\
\hline \multirow[t]{2}{*}{ Years $\times$ Years } & -0.0057 & -0.0058 & -0.0058 & -0.0059 \\
\hline & $(0.0040)$ & $(0.0040)$ & $(0.0041)$ & $(0.0041)$ \\
\hline \multirow[t]{3}{*}{ Announce } & $9.6406^{*}$ & $9.8093^{*}$ & $9.8663^{*}$ & $9.8784^{*}$ \\
\hline & $(1.4658)$ & $(1.4635)$ & $(1.4697)$ & $(1.4723)$ \\
\hline & \multicolumn{4}{|c|}{ Increase in web searches by performer type } \\
\hline \multirow[t]{2}{*}{ Band L } & $28.9272^{*}$ & $27.7799^{*}$ & $18.1074^{*}$ & $12.0826^{*}$ \\
\hline & $(2.4523)$ & $(2.0197)$ & $(1.5973)$ & $(1.3724)$ \\
\hline \multirow[t]{2}{*}{ Band M } & $33.0913^{*}$ & $28.5939^{*}$ & $16.5852^{*}$ & $12.1429^{*}$ \\
\hline & $(2.4063)$ & $(1.9819)$ & $(1.5673)$ & $(1.3465)$ \\
\hline \multirow[t]{2}{*}{ Band U } & $20.8713^{*}$ & $21.8125^{*}$ & $12.8704^{*}$ & $9.1425^{*}$ \\
\hline & $(2.7956)$ & $(2.3018)$ & $(1.8193)$ & $(1.5620)$ \\
\hline $\mathrm{N}$ & 18864 & 18864 & 18864 & 18864 \\
\hline AIC & 150172.3 & 150074.8 & 150269.2 & 150365.9 \\
\hline $\mathrm{BIC}$ & 150235.1 & 150137.6 & 150331.9 & 150428.7 \\
\hline
\end{tabular}

*p-value $<0.05$

Table 3: Fixed-effects models estimation results. Dependent variable: Google Trends search index in Spain. 

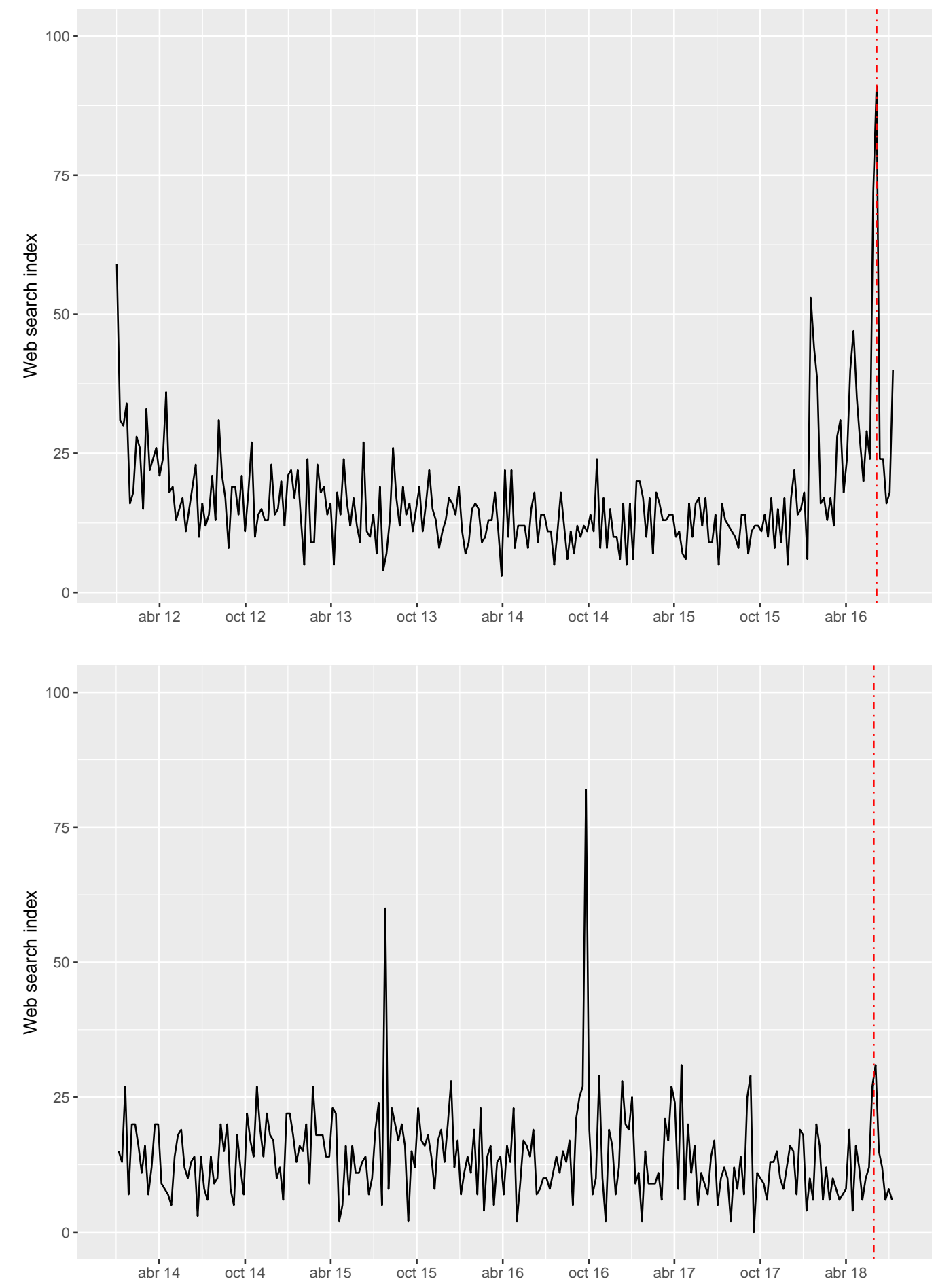

Figure 1: Time series of web search indices of two performers. On top: PJ Harvey (2016 Primavera Sound). On bottom: Jane Birkin (2018 Primavera Sound). The dashed reference line indicates the week the festival takes place. 


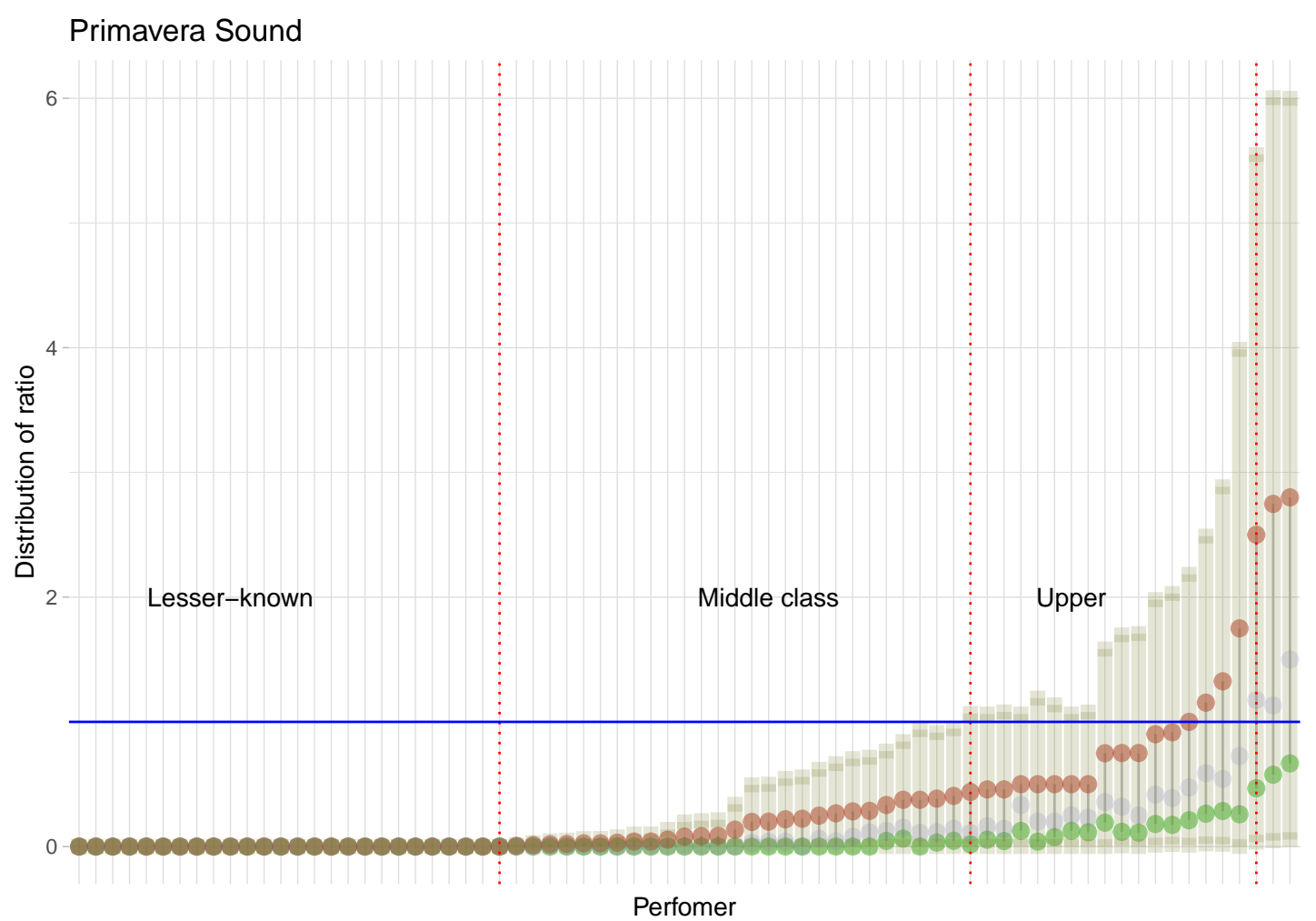

Figure 2: Distribution of the ratio of awareness. Performers are arranged in terms of their increasing relative awareness. For each one it shows: minimum (bottom whisker), median (dot) and maximum or 1.5 times the interquartile range (top whisker). 


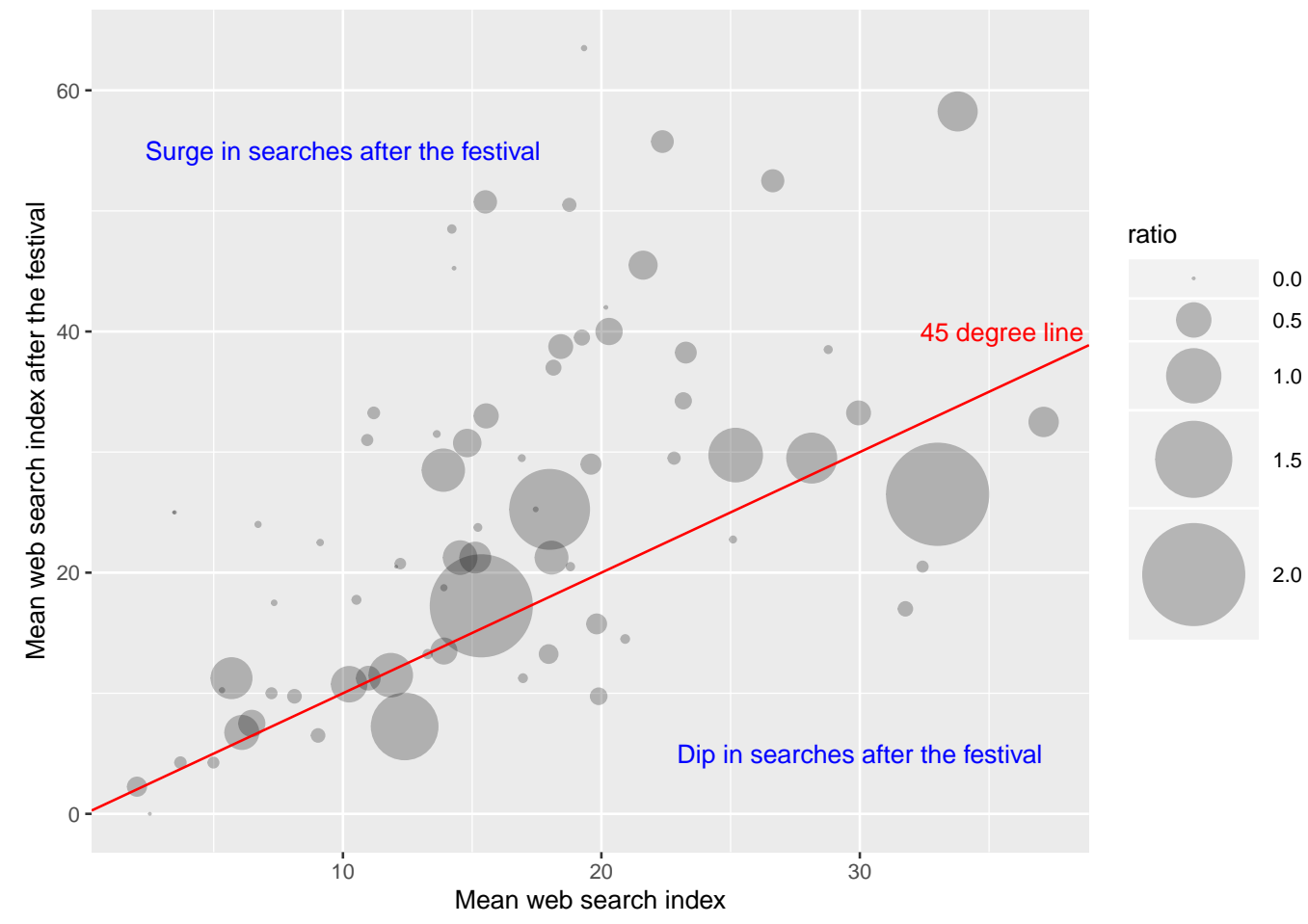

Figure 3: Scatterplot of the average index of web searches after the festival takes place against the average index for the whole sample. The size of each dot corresponds to the value of the ratio of web searches of each performer. The plot also includes the 45 degree line that splits performers that undergo a surge in searches after the festival takes place (above the line) and those that experience a dip in searches (below it). 

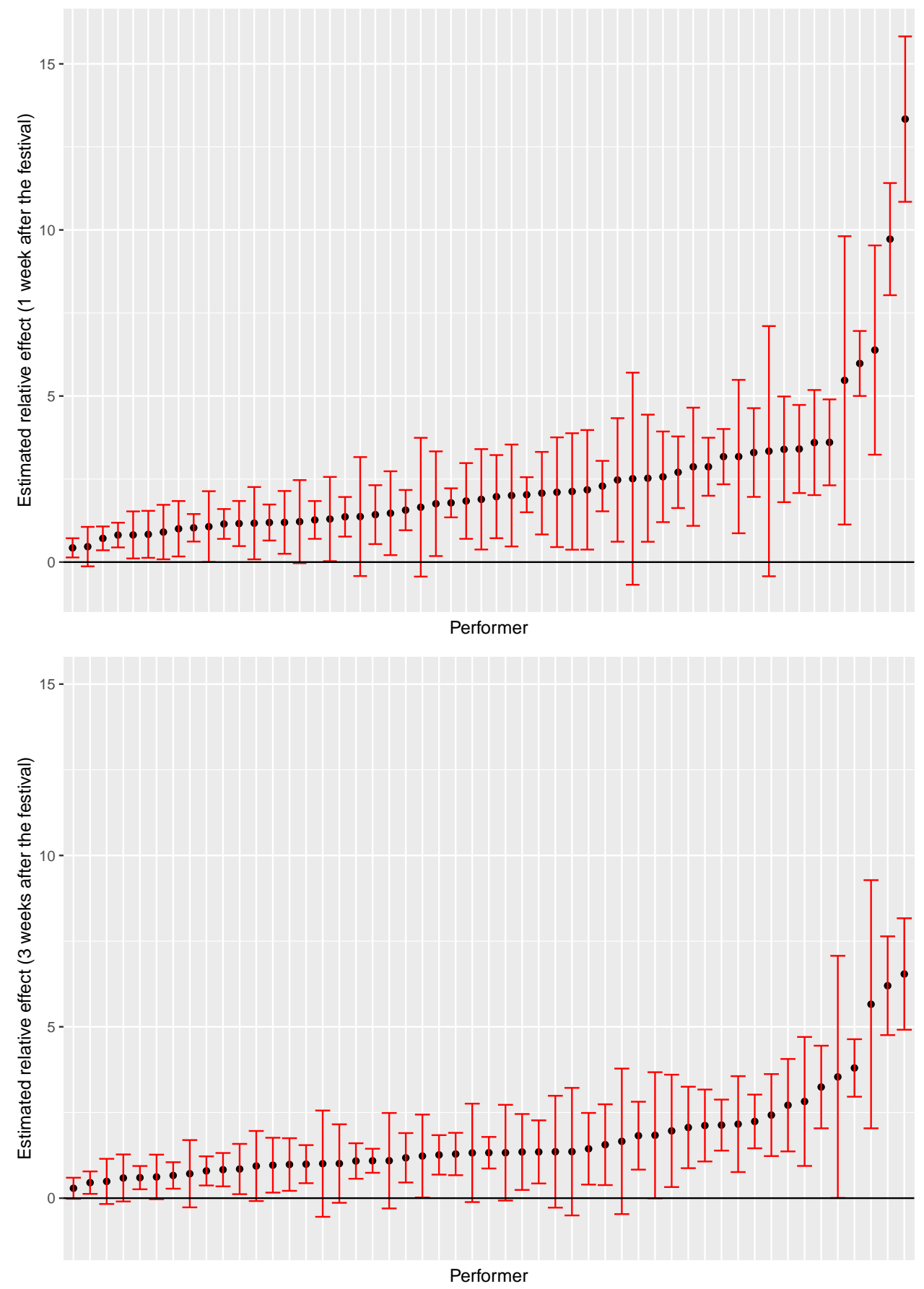

Figure 4: Estimated increase in web searches and 95\% confidence interval for performers in the sample one (top) and three (bottom) weeks after the festival. Performers are sorted by the magnitude of the impact. 


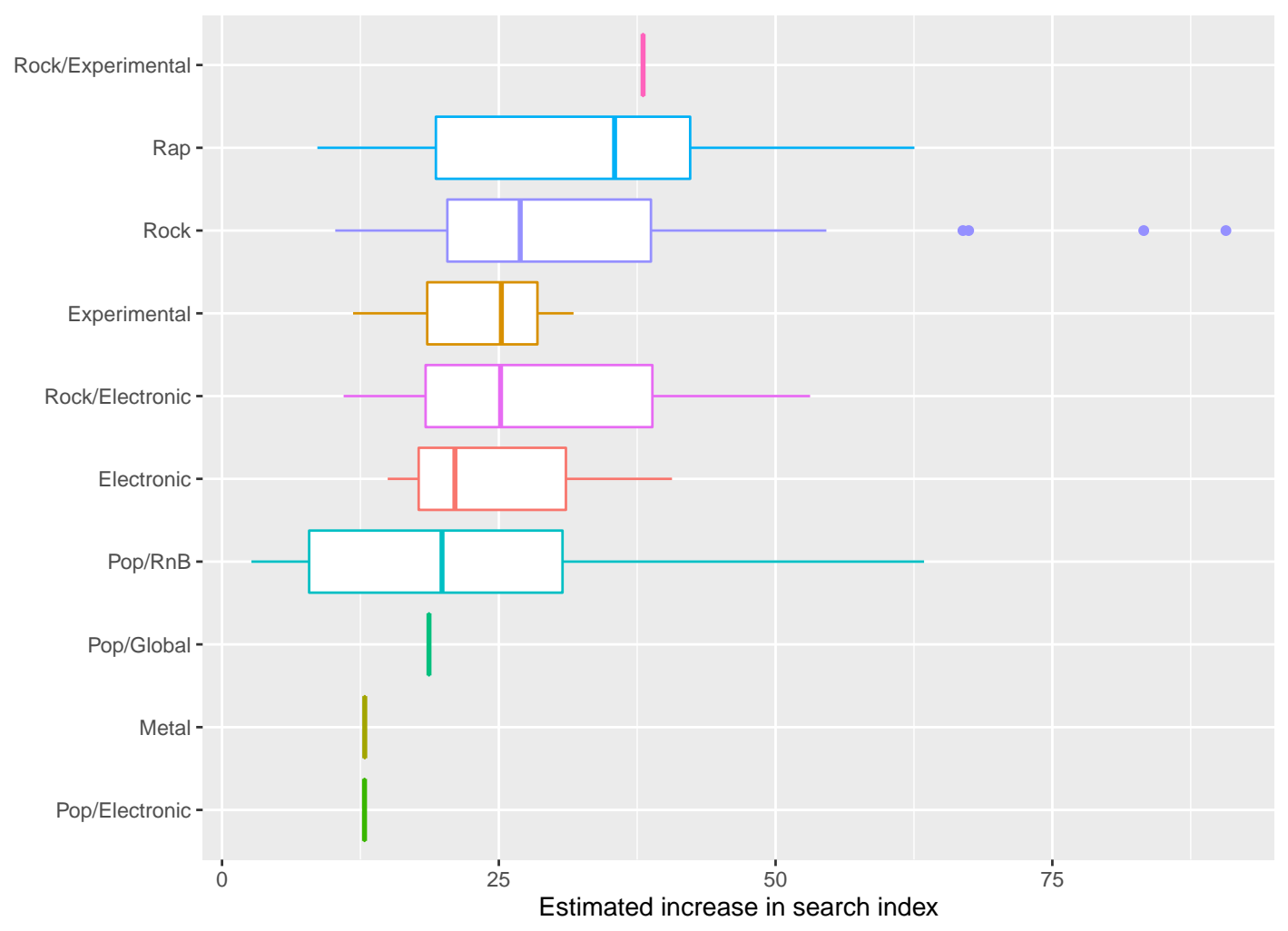

Figure 5: Distribution of the estimated increase in web searches across genres (one week after the festival).

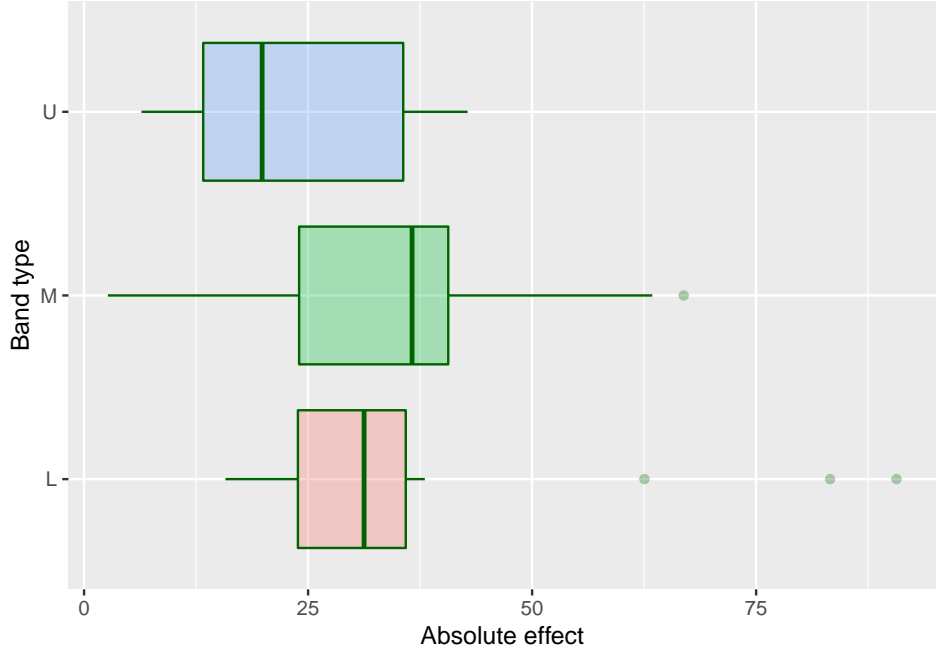

Figure 6: Distribution of the estimated absolute increase in the search index (one week after the festival) grouped by performer type. 


\section{Appendix}

\subsection{Description of the sample}

\begin{tabular}{|c|c|c|c|c|c|}
\hline Band & $\mathbf{1}^{\text {st }}$ album & Genre & Web & Ratio & Year \\
\hline $\mathrm{A} \$ \mathrm{AP}$ Rocky & 2011 & Rap & 31.04 & 0.57 & 2018 \\
\hline Action Bronson & 2011 & Rap & 12.02 & 0.02 & 2016 \\
\hline Angel Olsen & 2011 & Rock & 32.29 & 0.05 & 2017 \\
\hline Animal Collective & 2000 & Experimental & 3.56 & 0.02 & 2016 \\
\hline Aphex Twin & 1991 & Electronic & 17.42 & 0.09 & 2017 \\
\hline $\mathrm{ARCA}$ & 2014 & Experimental & 18.52 & 0.00 & 2018 \\
\hline Arcade Fire & 2003 & Rock & 11.04 & 0.58 & 2017 \\
\hline Arctic Monkeys & 2005 & Rock & 12.40 & 1.21 & 2018 \\
\hline Beach House & 2006 & Rock & 15.63 & 0.55 & 2016 \\
\hline Beirut & 2006 & Rock & 15.92 & 0.18 & 2016 \\
\hline Belle and Sebastian & 1996 & Rock & 9.83 & 0.08 & 2018 \\
\hline Bjork & 1993 & Pop/Electronic & 30.06 & 1.53 & 2018 \\
\hline Bon Iver & 2008 & Rock & 9.65 & 0.68 & 2017 \\
\hline Brian Wilson & 1988 & Rock & 32.85 & 0.27 & 2016 \\
\hline Charlotte Gainsbourg & 1986 & Pop/RnB & 4.73 & 0.25 & 2018 \\
\hline Chvrches & 2012 & Pop/RnB & 15.56 & 0.02 & 2018 \\
\hline Death Grips & 2011 & Experimental & 19.63 & 0.02 & 2017 \\
\hline Deerhunter & 2004 & Rock & 12.12 & 0.03 & 2016 \\
\hline Descendents & 1981 & Metal & 33.77 & 0.08 & 2017 \\
\hline Dinosaur Jr & 1985 & Rock & 21.85 & 0.01 & 2016 \\
\hline Drive Like Jehu & 1991 & Rock & 10.58 & 0.00 & 2016 \\
\hline Explosions in the Sky & 2000 & Rock & 6.33 & 0.01 & 2016 \\
\hline Father John Misty & 2012 & Rock & 17.00 & 0.13 & 2018 \\
\hline Fever Ray & 2009 & Electronic & 21.58 & 0.03 & 2018 \\
\hline Floating Points & 2009 & Electronic & 4.63 & 0.00 & 2018 \\
\hline Flying Lotus & 2006 & Electronic & 15.29 & 0.00 & 2017 \\
\hline Four Tet & 1998 & Electronic & 21.35 & 0.00 & 2018 \\
\hline
\end{tabular}

Continued on next page 


\begin{tabular}{|c|c|c|c|c|c|}
\hline Band & $\mathbf{1}^{\text {st }}$ album & Genre & Web & Ratio & Year \\
\hline Frank Ocean & 2001 & Pop/RnB & 10.17 & 1.25 & 2017 \\
\hline Grace Jones & 1977 & Rock/Electronic & 21.35 & 0.51 & 2017 \\
\hline Grizzly Bear & 2000 & Rock & 37.19 & 0.03 & 2018 \\
\hline Haim & 2013 & Rock & 26.12 & 0.27 & 2018 \\
\hline Jane Birkin & 1969 & Pop/RnB & 11.85 & 0.33 & 2018 \\
\hline Jon Hopkins & 1999 & Electronic & 14.83 & 0.01 & 2018 \\
\hline Last Shadow Puppets & 2008 & Rock & 21.71 & 0.11 & 2016 \\
\hline LCD Soundsystem & 2002 & Rock/Electronic & 9.92 & 0.04 & 2016 \\
\hline Lorde & 2013 & Pop/RnB & 7.00 & 1.15 & 2018 \\
\hline Lykke Li & 2004 & Pop/RnB & 16.98 & 0.11 & 2018 \\
\hline Mac Demarco & 2012 & Rock & 27.06 & 0.12 & 2017 \\
\hline Majid Jordan & 2014 & Pop/RnB & 31.15 & 0.00 & 2018 \\
\hline Metronomy & 2005 & Pop/RnB & 11.46 & 0.07 & 2017 \\
\hline Migos & 2015 & Rap & 37.25 & 0.70 & 2018 \\
\hline Miguel & 2008 & Pop/RnB & 34.08 & 0.44 & 2017 \\
\hline Moderat & 2003 & Electronic & 25.87 & 0.07 & 2016 \\
\hline Mogwai & 1997 & Rock & 15.98 & 0.18 & 2018 \\
\hline Nick Cave & 1983 & Rock & 5.13 & 0.53 & 2018 \\
\hline Nils Frahm & 2009 & Electronic & 16.31 & 0.00 & 2018 \\
\hline PJ Harvey & 1991 & Rock & 21.21 & 0.25 & 2016 \\
\hline Pusha T & 2011 & Rap & 14.42 & 0.01 & 2016 \\
\hline Radiohead & 1992 & Rock & 19.94 & 1.72 & 2016 \\
\hline Richard Hawley & 2001 & Rock & 9.75 & 0.16 & 2016 \\
\hline Run The Jewels & 2013 & Rap & 12.98 & 0.02 & 2017 \\
\hline Sigur Ros & 1997 & Rock & 10.50 & 0.37 & 2016 \\
\hline Skepta & 2007 & Rap & 22.06 & 0.11 & 2017 \\
\hline Slayer & 1983 & Metal & 10.38 & 0.70 & 2017 \\
\hline Slowdive & 1990 & Rock & 18.63 & 0.07 & 2018 \\
\hline Solange & 1999 & Pop/RnB & 2.13 & 0.31 & 2017 \\
\hline Spiritualized & 1990 & Rock/Experimental & 13.02 & 0.00 & 2018 \\
\hline
\end{tabular}

Continued on next page 


\begin{tabular}{lllrrr}
\hline Band & $\mathbf{1}^{\text {st }}$ album & Genre & Web & Ratio & Year \\
\hline Suede & 1992 & Rock & 11.44 & 0.30 & 2016 \\
Tame Impala & 2008 & Rock & 35.42 & 0.76 & 2016 \\
Teenage Fanclub & 1990 & Rock & 9.48 & 0.20 & 2017 \\
The Blaze & 2017 & Electronic & 4.40 & 0.00 & 2018 \\
The Breeders & 1990 & Rock & 17.44 & 0.03 & 2018 \\
The Internet & 2011 & Pop/RnB & 16.85 & 0.00 & 2018 \\
The Magnetic Fields & 1990 & Rock & 28.81 & 0.03 & 2017 \\
The Make Up & 1996 & Rock & 10.27 & 0.00 & 2017 \\
The National & 2001 & Rock & 16.42 & 0.63 & 2018 \\
The War on Drugs & 2008 & Rock & 35.12 & 0.31 & 2018 \\
The XX & 2009 & Pop/Electronic & 29.12 & 2.07 & 2017 \\
Tyler the Creator & 2009 & Rap & 34.38 & 0.33 & 2018 \\
Van Morrison & 1967 & Rock & 29.17 & 1.08 & 2017 \\
Vince Staples & 2014 & Rap & 11.46 & 0.01 & 2016 \\
\hline
\end{tabular}

Table 4: Description of the sample and main summary statistics.

\subsection{Detailed estimation results}

\begin{tabular}{lrrrrrrr}
\hline & \multicolumn{3}{c}{ One week } & \multicolumn{4}{c}{ Three weeks } \\
Artist & Relative effect & s.e. & pval & Relative effect & s.e. & pval \\
\hline A \$AP Rocky & 1.15 & 0.23 & 0.00 & 0.67 & 0.21 & 0.00 \\
Action Bronson & 1.01 & 0.50 & 0.02 & 0.49 & 0.40 & 0.14 \\
Angel Olsen & 1.00 & 0.43 & 0.01 & 1.12 & 0.34 & 0.00 \\
Animal Collective & 5.47 & 2.21 & 0.01 & 2.34 & 1.64 & 0.08 \\
Aphex Twin & 1.56 & 0.31 & 0.00 & 0.99 & 0.29 & 0.00 \\
ARCA & 1.65 & 1.07 & 0.06 & 0.67 & 0.79 & 0.20 \\
Arcade Fire & 3.61 & 0.66 & 0.00 & 2.03 & 0.63 & 0.00 \\
Arctic Monkeys & -0.12 & 0.21 & 0.28 & -0.38 & 0.19 & 0.02 \\
Beach House & 0.54 & 0.87 & 0.27 & 0.30 & 1.04 & 0.39 \\
Beirut & 0.38 & 0.70 & 0.30 & 0.30 & 0.58 & 0.31 \\
\hline
\end{tabular}

Continued on next page 
One week

Three weeks

Artist

Relative effect s.e. pval Relative effect s.e. pval

\begin{tabular}{|c|c|c|c|c|c|c|}
\hline Belle and Sebastian & 2.53 & 0.98 & 0.01 & 2.56 & 0.97 & 0.00 \\
\hline Bjork & 0.47 & 0.30 & 0.06 & 0.07 & 0.27 & 0.39 \\
\hline Bon Iver & 2.87 & 0.91 & 0.00 & 1.52 & 0.78 & 0.03 \\
\hline Brian Wilson & 1.95 & 0.34 & 0.00 & 0.84 & 0.30 & 0.00 \\
\hline Charlotte Gainsbourg & 1.80 & 1.98 & 0.17 & 1.07 & 1.78 & 0.27 \\
\hline Chvrches & 0.84 & 0.36 & 0.01 & 0.29 & 0.34 & 0.20 \\
\hline Death Grips & 1.84 & 0.58 & 0.00 & 0.81 & 0.35 & 0.01 \\
\hline Deerhunter & 2.79 & 0.84 & 0.01 & 1.30 & 0.86 & 0.07 \\
\hline Descendents & -0.09 & 0.36 & 0.40 & -0.27 & 0.27 & 0.15 \\
\hline Dinosaur Jr & 0.96 & 0.49 & 0.03 & 0.91 & 0.40 & 0.01 \\
\hline Drive Like Jehu & 3.30 & 0.41 & 0.00 & 1.88 & 0.35 & 0.00 \\
\hline Explosions in the Sky & 1.88 & 0.29 & 0.00 & 0.86 & 0.22 & 0.00 \\
\hline Father John Misty & 2.71 & 0.55 & 0.00 & 1.25 & 0.47 & 0.01 \\
\hline Fever Ray & 1.17 & 0.56 & 0.02 & 0.72 & 0.51 & 0.08 \\
\hline Floating Points & 3.34 & 1.92 & 0.04 & 2.88 & 1.50 & 0.02 \\
\hline Flying Lotus & 0.63 & 0.78 & 0.21 & 0.50 & 0.63 & 0.21 \\
\hline Four Tet & 0.88 & 0.80 & 0.13 & 0.21 & 0.63 & 0.39 \\
\hline Frank Ocean & 0.90 & 0.42 & 0.02 & 0.40 & 0.34 & 0.12 \\
\hline Grace Jones & 2.29 & 0.39 & 0.00 & 1.12 & 0.28 & 0.00 \\
\hline Grizzly Bear & 1.07 & 0.54 & 0.03 & 0.20 & 0.42 & 0.31 \\
\hline Haim & 2.57 & 0.70 & 0.00 & 1.10 & 0.62 & 0.03 \\
\hline Jane Birkin & 2.18 & 0.92 & 0.01 & 1.13 & 0.72 & 0.06 \\
\hline Jon Hopkins & 0.05 & 0.41 & 0.44 & -0.02 & 0.35 & 0.48 \\
\hline Last Shadow Puppets & 0.56 & 0.16 & 0.00 & 0.13 & 0.14 & 0.17 \\
\hline LCD Soundsystem & 6.77 & 0.39 & 0.00 & 3.40 & 0.31 & 0.00 \\
\hline Likke Li & 2.87 & 0.45 & 0.00 & 1.54 & 0.37 & 0.00 \\
\hline Lorde & 2.51 & 1.63 & 0.06 & 1.13 & 1.77 & 0.26 \\
\hline Mac Demarco & 0.81 & 0.19 & 0.00 & 0.40 & 0.16 & 0.01 \\
\hline Majid Jordan & 1.22 & 0.64 & 0.03 & 0.61 & 0.46 & 0.09 \\
\hline
\end{tabular}

Continued on next page 
One week

Three weeks

Artist

Relative effect s.e. pval Relative effect s.e. pval

\begin{tabular}{|c|c|c|c|c|c|c|}
\hline Metronomy & 0.46 & 0.74 & 0.27 & 0.15 & 0.74 & 0.42 \\
\hline Migos & 1.78 & 0.22 & 0.00 & 1.15 & 0.17 & 0.00 \\
\hline Miguel & 0.32 & 0.37 & 0.19 & 0.20 & 0.29 & 0.25 \\
\hline Moderat & 1.52 & 0.25 & 0.00 & 0.72 & 0.23 & 0.00 \\
\hline Mogwai & 1.45 & 1.21 & 0.11 & 0.52 & 1.05 & 0.31 \\
\hline Nick Cave & 3.60 & 0.81 & 0.00 & 1.52 & 0.59 & 0.01 \\
\hline Nils Frahm & 0.12 & 0.48 & 0.40 & 0.06 & 0.37 & 0.44 \\
\hline PJ Harvey & 2.07 & 0.20 & 0.00 & 1.05 & 0.21 & 0.00 \\
\hline Pusha T & 1.07 & 0.59 & 0.04 & 0.80 & 0.69 & 0.11 \\
\hline Radiohead & 0.44 & 0.13 & 0.00 & 0.19 & 0.15 & 0.10 \\
\hline Richard Hawley & 0.87 & 0.91 & 0.17 & 0.53 & 0.90 & 0.27 \\
\hline Run The Jewels & 3.41 & 0.68 & 0.00 & 1.58 & 0.46 & 0.00 \\
\hline Sigur Ros & 2.28 & 0.99 & 0.01 & 1.41 & 1.01 & 0.07 \\
\hline Skepta & 1.43 & 0.45 & 0.00 & 0.59 & 0.35 & 0.05 \\
\hline Slayer & 1.16 & 0.35 & 0.00 & 0.53 & 0.35 & 0.06 \\
\hline Slowdive & 1.89 & 0.77 & 0.01 & 0.59 & 0.68 & 0.19 \\
\hline Solange & 1.97 & 0.64 & 0.00 & 0.93 & 0.47 & 0.03 \\
\hline Spiritualized & 3.18 & 1.18 & 0.00 & 2.66 & 0.83 & 0.00 \\
\hline Suede & 3.58 & 0.70 & 0.00 & 1.68 & 0.63 & 0.00 \\
\hline Tame Impala & 1.29 & 0.31 & 0.00 & 0.65 & 0.32 & 0.02 \\
\hline Teenage Fanclub & 0.06 & 0.70 & 0.45 & -0.20 & 0.60 & 0.36 \\
\hline The Blaze & -1.00 & 3.69 & 0.39 & -1.00 & 2.07 & 0.31 \\
\hline The Breeders & 1.30 & 0.65 & 0.02 & 0.74 & 0.50 & 0.06 \\
\hline The Internet & 0.71 & 0.89 & 0.22 & 0.30 & 0.65 & 0.33 \\
\hline The Magnetic Fields & 1.20 & 0.48 & 0.01 & 0.59 & 0.35 & 0.04 \\
\hline The Make Up & 13.34 & 1.27 & 0.00 & 5.11 & 0.83 & 0.00 \\
\hline The National & 2.10 & 0.84 & 0.01 & 1.19 & 0.67 & 0.04 \\
\hline The War on Drugs & 2.08 & 0.63 & 0.00 & 0.89 & 0.61 & 0.07 \\
\hline The XX & 0.28 & 0.28 & 0.16 & 0.08 & 0.31 & 0.39 \\
\hline
\end{tabular}

Continued on next page 


\begin{tabular}{lrrrrrrr}
\hline & \multicolumn{3}{c}{ One week } & \multicolumn{4}{c}{ Three weeks } \\
Artist & Relative effect & s.e. & pval & Relative effect & s.e. & pval \\
\hline Tyler the Creator & 1.36 & 0.30 & 0.00 & 1.00 & 0.24 & 0.00 \\
Van Morrison & 1.19 & 0.28 & 0.00 & 0.58 & 0.24 & 0.01 \\
Vince Staples & 1.27 & 0.51 & 0.01 & 0.90 & 0.52 & 0.04 \\
\hline
\end{tabular}

Table 5: Results: estimated effects. 